\title{
Hybrid Copyright Protection Model for Secured Multimedia and Digital Resource Utilization
}

\author{
Igboji Kingsley $\mathbf{O}$. \\ Department of Computer Science, Ebonyi State University, Abakaliki, Nigeria
}

Email address:

tubok@yahoo.com

To cite this article:

Igboji Kingsley O. Hybrid Copyright Protection Model for Secured Multimedia and Digital Resource Utilization. International Journal of Science and Qualitative Analysis. Vol. 3, No. 2, 2017, pp. 10-14. doi: 10.11648/j.ijsqa.20170302.11

Received: August 27, 2016; Accepted: September 10, 2016; Published: October 10, 2017

\begin{abstract}
Copyright protection is a mechanism to secure the rights of ownership of original work so that no one can use the rights-protected work in any way without seeking permission for the use. It became imperative that user may pay the right owners a royalty for utilizing such resource. Copyright Society of Nigeria(COSON) is the regulatory body over intellectual properties but it lacks provision for encrypting digital content like videos, images and graphics. Hence, rampart illicit reproduction of developed graphics, movies, images and music by internet mafias and thereby deprive legitimate owners their due proceeds. This anomaly led to development of copyright protection suite to competently secure copyrighted infrastructures and create a viable interface between COSON and content owners. All original digital contents are encrypted, interested user are made to pay royalty before access is allowed. Structured system analysis and design approach is deployed in developing the system - which provides clear cut steps in navigating process-to-process. The implementation used server side scripting language with its associated embedded resources and Standard Query Language(MySQL)to achieve the desired input-output robustness and buoyant security fittings.
\end{abstract}

Keywords: Copyright, COSON, Repositories, Encryption, Digital Contents, Royalty

\section{Introduction}

Copyright is an exclusive right granted to the authors or creators of "original works", published or unpublished. It could be fixed in a tangible medium either hard or digital/electronic copies. Copyright provides not just a single right, but a bundle of rights that can be exploited or licensed separately or together. This right applies to multimedia and varying digital piece. Multimediais any appropriate combination of text, images, animation, sound and video for the purpose of electronic communication of information. These elements are encased in repositories technically known as digital content.

\subsection{Security Resolutions}

Routine trends of advancements in Internet technologies and increasing demands on online multimedia businesses, digital copyright has become a major concern for businesses that engage in online content distribution through various business models, such as pay-per-view, subscription, trading, etc. This is largely due to the fact that a perfect copy of the distributed content can be reproduced at almost-zero cost. According to Frattolillo and Landolfi (2008), digital piracy results due to the ease by which copying and sharing files on the Internet are done. The emergence of peer-to-peer networks in the beginning of the millennium has led to rapid development of illegal file sharing processes especially touching music and videos (Einhora and Rosenblatt, 2005). Consequent upon which unimaginable dramatic revenue losses ensue due to copyright infringement at its alarming rate.

\subsection{Brief Historic Review of Topical Issue}

Although copyright protection is an active research, quite a little has been carried on safeguarding e-Course and no effective approach for copyright detection in the domain of eEducation. Daily, people in their chosen field of technological innovations engage both time and talent developing diverse product with a view to making name and profit. Sadly, there end up losing out as these products are trapped illegally by unauthorized persons who dubiously 
duplicates and distribute same for their own gains. A digital article is regarded as illegally printed if it contains no bar code on its front page as well invisible watermarks inserted into other spots in the digital document. Tracing these invisible watermarks can reveal any illegal act performed on the content. Swanson, et al. (1998) identified the requirements for the application of copyright protection that watermarking must embed the ownership of the content when the content is being duplicated or abused. Watermarking is a technique for media authentication and forgery prevention and it is viewed as an enabling technology to protect media from reuse without adequate credit or in an unauthorized way (Trowbridge, 1995).

Obviously, various means adopted to curb the menace of copyright infringements has only yielded very minor result. This is predominantly due to lack of adequate security measures to protect the resource and non-functional electronic means for collecting royalties from end users. Moreover, the Copyright Society of Nigeria offered none, hence this robust mechanism that interfaces COSON, content owners and users.

\section{Conceptual Views}

Intellectual property right is a pressing concern for content owners who are exhibiting digital representations of photographs, rare books/manuscripts and original digital content on the World Wide Web platforms (Dittmann, et al. 2002). Apparently, revolutions in digital technologies gave rise to new opportunities and threats across the economic and social system. The copyright system, which has its origins in the Statute of Anne 1710 and was developed substantially in the 19century, has come under intense pressure. The ability to copy and disseminate others' creative work at very low cost has given rise to the issues of illegal file sharing and 'piracy'. New consumer electronic devices have given consumers the ability to adapt and create new work, known as usergenerated content (Boyer, 2007).

Copyright Society of Nigeria COSON is a company limited by guarantee and incorporated under the laws of Nigeria as a not-for-profit company. It is approved by the Nigerian Copyright Commission to operate as the sole
Collective Management Organization (CMO) for musical works and sound recordings in Nigeria; COSON is authorized to license the public and commercial use of musical works and sound recordings. In the UK the Gowers (2006), review in 2006 put forward 54 recommendations concerned with developing the existing legal and policy framework for intellectual property rights, with a strong focus on copyright. Some of these recommendations concerned copyright exceptions. On a legal reading of the term 'copyright exception', consumers or other agents can use copyrighted material in specified ways without violating copyright (Australian Copyright Council, 2001).

\section{Materials and Methods}

Vital instruments as deemed appropriate were deployed to get the work done. These includes the use of structured system analysis and design approach for coherence and efficient phase-by-phase development, data flow diagram (DFD), Entity Relation Diagram (ERD) and flow charts which afforded proper flow of signal across the system. Implementation utilizedencryption algorithm for logical expressions and Adobe Macromedia Dreamweaver CS3 with relevant embedded scripting languages to achieve a userfriendly and simplified creation of attractive web pages. Also, a virtual server Xampp (Cross platform, Apache, MYSQL, Perl and PHP) that is not operating system dependent was used to achieve end-to-end operation.

\section{Discussion}

Series of technical and logical procedure has been duly followed as deemed appropriate at various phases of development. Adequate and suitable tools were equally adopted to implement a functional model.

\subsection{Contextual Analysis}

The context diagram below shows the variuous users that will be using the system and the kind of information that the users will be supplying to the system. The context diagram is displayed below:

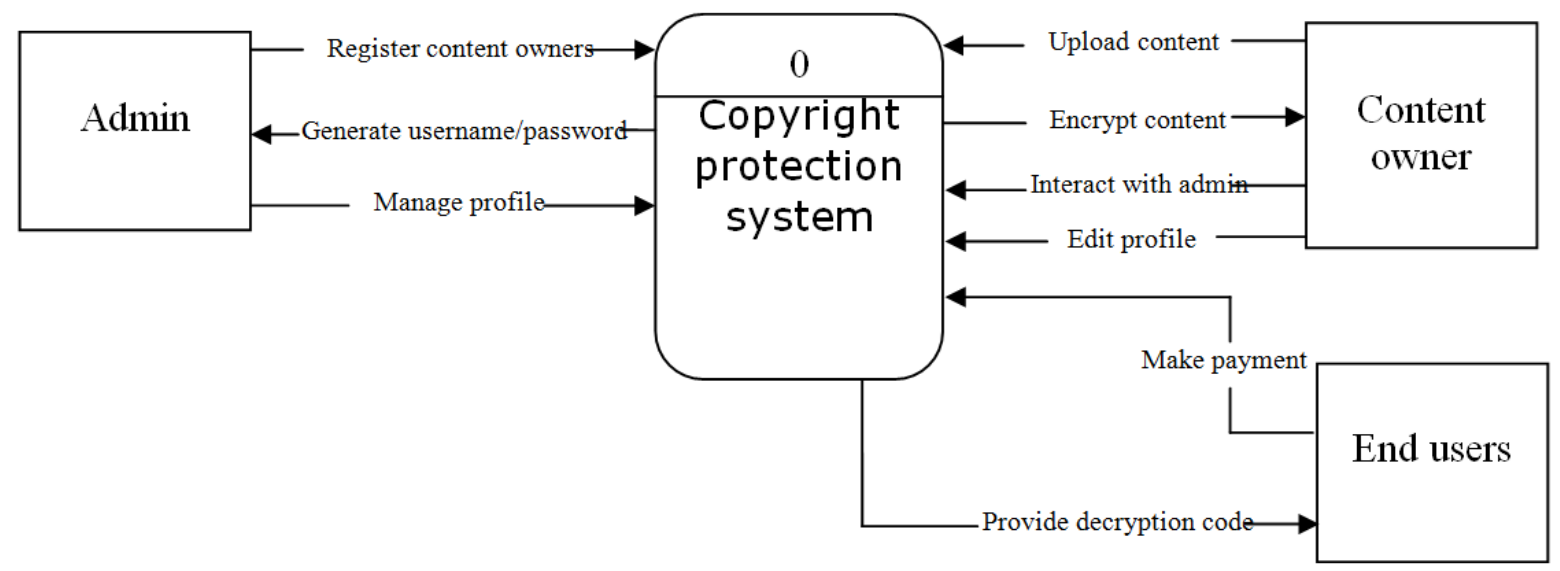

Figure 1. Context Diagram. 
The context diagram above depicts the way in which the copyright protection system interacts with the Admin, content owners, and End users. Admin will register content owners, the system automatically generate username and password for the content owner to gain access to the system subsequently.
Thereafter, the content owner will login with the username and password to upload content, the system automatically encrypts the uploaded content, the content owner can also interact with the admin and also edit its profile. If an end user makes payment, after due confirmation, the decryption code will be visible with which to download the contents.

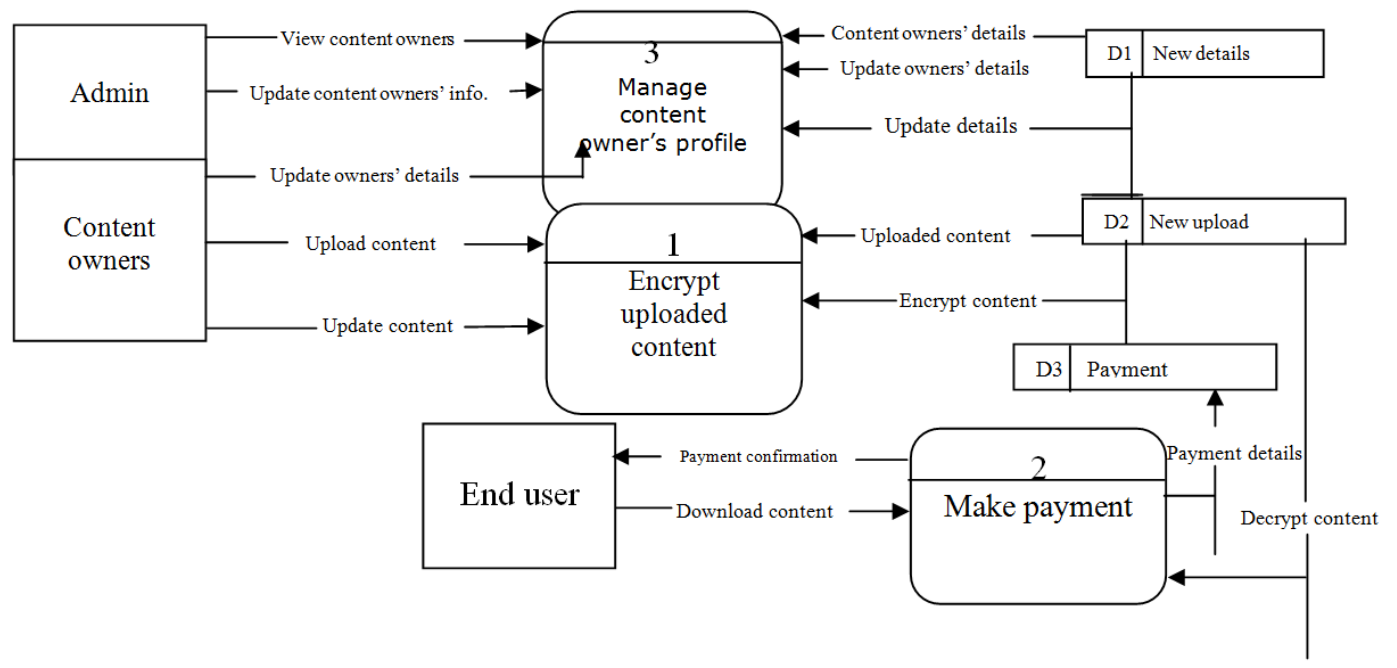

Figure 2. System Context Level 0 DFD of the System.

In the level 0 diagram above, the admin can manage content owner's profile which is being stored in data store "New details", via "Manage content owner's profile process. Customer can manage its profile which is been stored in admin via "manage content owners profile process", upload content and update content after which the system automatically encrypt content via "encrypt uploaded content process" and the uploaded content is stored in new upload. And lastly the end users will make payment via "make payment process", after payment has been made then the decryption code will be visible to the end users to enable them download the content via payment data store.

\subsection{Data Model Analysis}

Data model describes the data that flow through the copyright protection system processes. Figure 3 below shows an Entity Relationship diagram that describes the relationship, attributes and properties between admin and content owner using the tool that was developed by (Peter Chen, 1976).

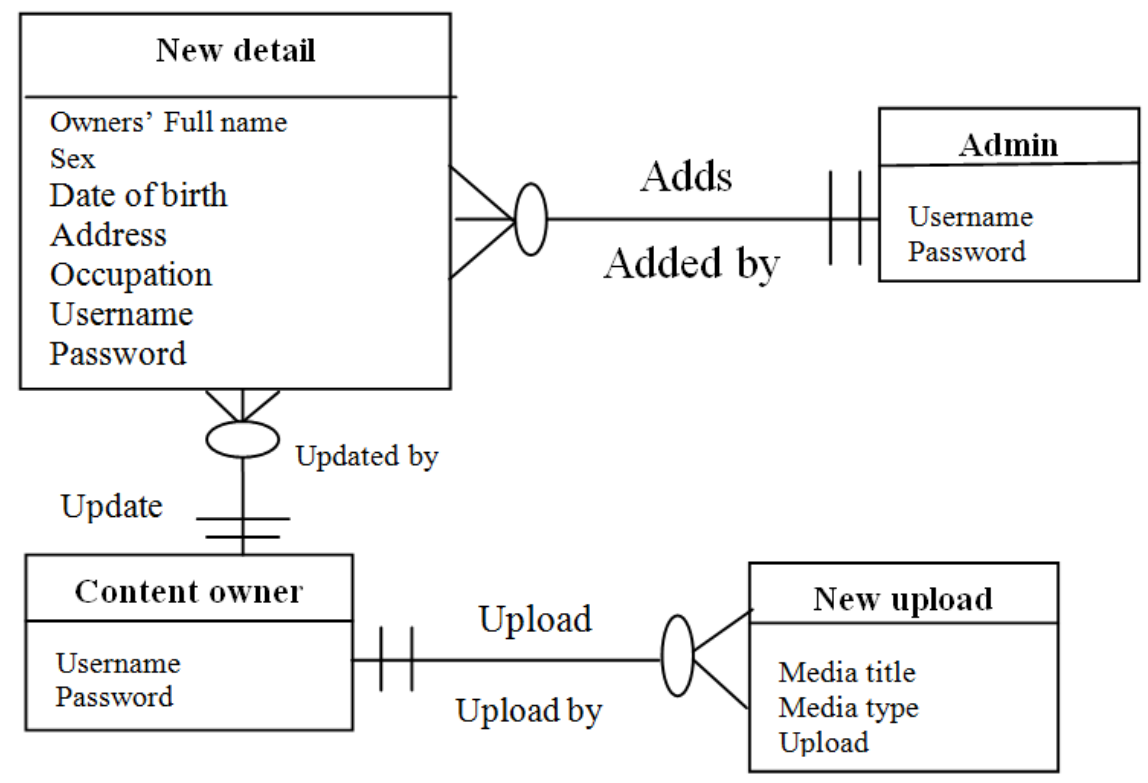

Figure 3. Entity Relationship Diagram (Peter Chen, 1976). 
In the above ERD, admin register content owners. Content owner will login to the system to update profile and upload content.

\subsection{Implementing the High Level Model}

The block architectural representation of module-tomodule flow of traffic across the system is other to enhance efficient interactions among coordinate components. The design splits into three subs having proper interactive process which incorporates the administrator, the content owner and the user platform.

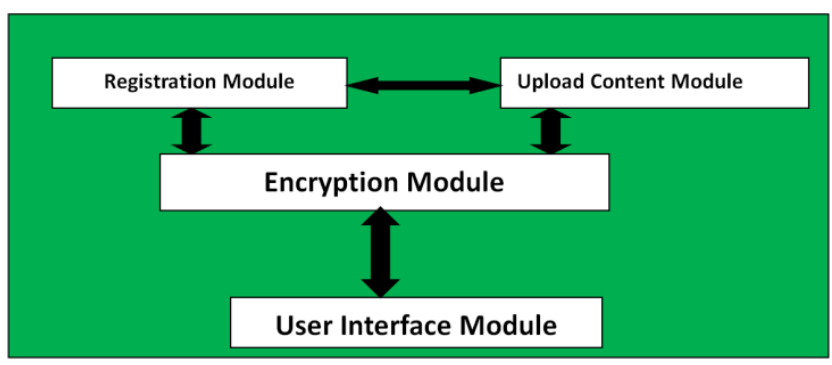

Figure 4. Block Diagram of the HLM.

As shown above, the system is designed into modules thus; Registration Module: enable the admin register content owners by allocating username and password used to login/access the system; Uploading Module: enables the content owners to upload their digital content and subsequent automatic encryption of the content; Encryption Module: enables the content to be secured and prevented from unauthorized access with RC2 algorithm. The RC2 encrypts data in (64-bit data blocks, 8 to 128 bits variable key), and generate 8-bit increments using cipher text to hide the decryption code until royalty proof is provided before the cipher text will be converted to plaintext; Downloading Module: enables end users to gain access to the content after due confirmation of royalty payment - decryption key is displayed to the user for requisite download of content.

\subsection{Main Menu Interface}

Here comes the point of access that holds the connections or links to other available pages. The main menu implementation shown in figure 5 a provides background tips and entry to the main interface with correct login details. Both admin, content owners and users observes it before advancing to other level of usage as applicable through figure $5 \mathrm{~b}$ menu.

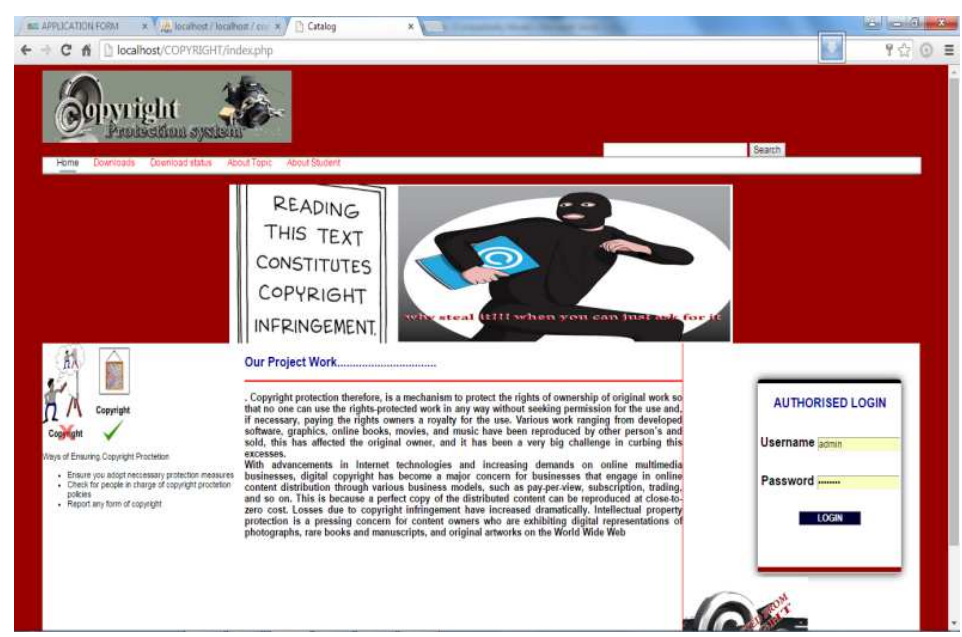

Figure 5a. Login Interface.

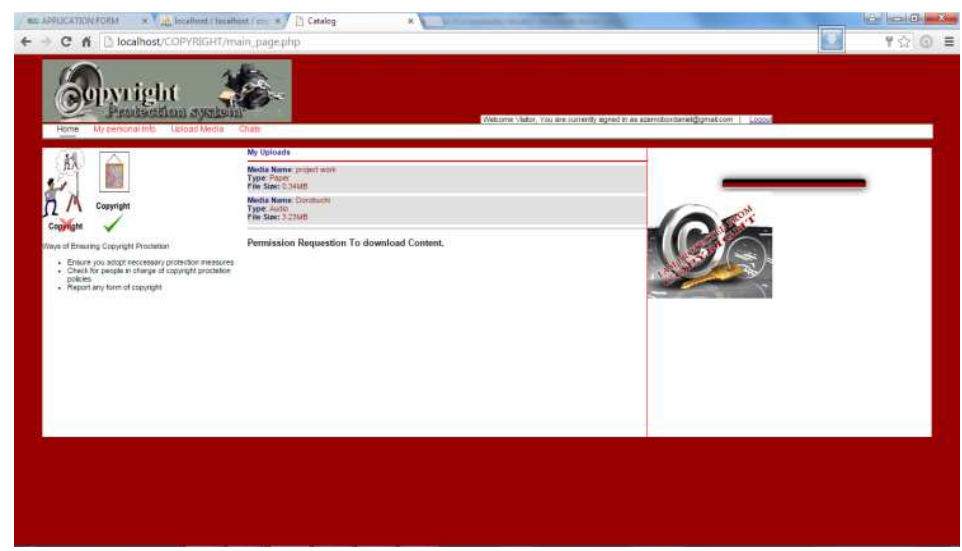

Figure 5b. Main Menu Interface. 


\section{Conclusion}

The system presents new formidable technical advances and credible resort that forestall persistent attempts of social miscreants to trap down classical documents. It portends functional electronic means for managing all forms of copyrighted digital and multimedia resource which are well secured via encryption algorithm. Its robust interface creates interactivity between copyright regulatory body, content owners and interested users pay royalty to access any resource.

Therefore, it is pertinent to say that this mechanism is timely in clamping down on the ever increasing cases of copyright infringement on intellectual properties. Access to copyrighted material will undergo routine process of approval that will not just accord sense of ownership to content owners but will generate funds through royalty remittance.

\section{References}

[1] Australian Copyright Council (2001). 'Remuneration for Private Copying in Australia, A Discussion Paper' Australian Mechanical Copyright Owners Society (AMCOS) \& Screenrights (2001). 'The Case for a Private Copying Levy'.

[2] Boyer, M. (2007). The Economics of Copyright and Fair Dealing. Scientific Series, December, Centre Interuniversitaire de Recherche en Analyses des Organizations (CIRANO).

[3] Einhora, M. A., and Rosenblatt, B. (2005). Peer-to-Peer
Networking and Digital Rights Management: How market tools can solve copyright problems. Carto Institute Policy Analsis no. 534.

[4] Frattolillo, F., and Landolfi, F. (2008). "Designing a DRM System", in Proceeding of the Fourth International Symposium on Information Assurance and Security, IEEE Computer Society - Los Alamitos, CA. pp 221.

[5] Gowers, A. (2006). The Gowers Review of Intellectual Property. Report for the UK Treasury, http://www.hmtreasury.gov.uk/independent_reviews/

[6] Peitz, M., and Waelbroeck, P. (2004). 'The Effect of Internet Piracy on CD Sales: Cross-Section Evidence'. CESifo Working Paper No. 1122.

[7] Rogers, and Thomas, (2007). 'Fair Use in the US Economy, Economic Contribution of Industries Relying on Fair Use.' Computer \& Communications Industry Association.

[8] Swanson, J (1998). 'Integrating Consumer Rights into Copyright Law From a European Perspective.' Journal of Consumer Policy, vol. 31, no. 4. The Printing Group (2006) 'Statement on Copyright Levies on Multifunctional Printers and Printers.'

[9] Trowbridge, R (1995). 'Why has Cultural Economics Ignored Copyright?' The Journal of Cultural Economics 32 243-259. Towse, R., C. Handke and P. Stepan (2008). 'The Economics of Copyright Law: A Stocktake of the Literature.'

[10] Weatherall, K (2005). 'A Comment on the Copyright Exceptions Review and Private Copying.' Intellectual Property Research Institute of Australia, Working Paper No. $14 / 05$. 